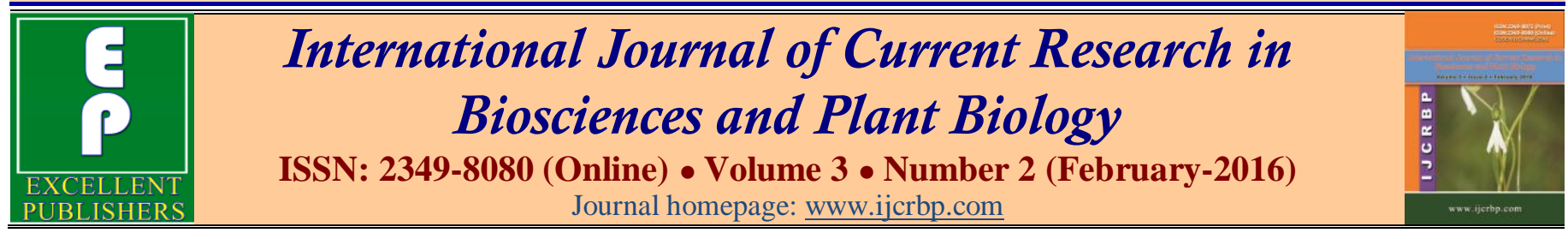

\title{
Phytochemical Evaluation of Withanolide-A in Ashwagandha Roots from Different Climatic Regions of India
}

\author{
Rehana Anjum Shah*, Shahana Khan, Wahida Rehman and Moinuddin Vakil \\ Department of Botany, The Institute of Science, 15, Madame Cama Road, Mumbai-40o o32, India \\ *Corresponding author.
}

\begin{abstract}
A bstract
Ashwagandha [Withania somnifera (L.) Dunal] is a highly valued medicinal plant in Ayurveda, used either singly or in combination with other herbs. Plants growing under different agro-climatic condition often show qualitative and quantitative variations in their phytoconstituents. In the GC-MS analysis, 24 bioactive phytochemical compounds were identified in roots and leaves of Withania somnifera. Present investigation deals with comparison of Ashwagandha plants (WsL, WsK, WsN and WsM) obtained from various regions (Lucknow, Karnataka, Nimuch and Mumbai) of India, for their withanolide-A contents using HPTLC. Methanolic root extracts of WsN showed maximum withanolide-A content (1.3\%), WsK being close behind at $1.2 \%$ followed by WsM $(0.7 \%)$; WsL showed minimum withanolide-A content at $0.4 \%$ only.
\end{abstract}

\section{Article Info}

Accepted: 29 January 2016

Available Online: 06 February 2016

Ke ywords

Ashwagandha

Medicinal plant

Phytochemical compounds

Withanolide-A

\section{Introduction}

Withania somnifera (L.) Dunal, commonly known as 'Ashwagandha' belongs to family-Solanaceae. Ashwagandha sometimes referred to as Indian ginseng, is a valued herb in Ayurveda and has been cultivated for centuries in India. Ayurvedic Pharmacopoeia of India cites it as a strengthening tonic, aphrodisiac, and for the treatment of arthritis. It's the primary component of numerous traditional Ayurvedic tonics and anti aging compounds (Ayurvedic Pharmacopoeia of India, 1985; Tripathi et al., 1996).

The primary constituents of interest in Ashwagandha are alkaloids and steroidal lactones the latter of which are known as withanolides. Alkaloids constitute about 0.3$4.3 \%$ of total constituents. Several withanolides are identified in Ashwagandha including withanolides A-Y (Tripathi et al., 1996). There are as many as 40 similar structures synonymously identified in the literature as withaferin-A (Kapoor, 1990.). Withanolide-A is also the major compound of Withania somnifera and is a biologically active steroidal lactone. The present research work is aimed to describe the phytochemical variations among different climatic regions.

At least five different morpho, chemo and geographic forms have been identified in this species, though names have not been assigned to them. The five primary chemotypes originate from different areas and are categorized as Form I to Form V. Form I is cultivated in Madhya Pradesh and is the primary source of commercial material in India. Form II originates from sandy deserts of Rajasthan, Form III grows in Chandigarh and other mountainous area of Punjab, Form IV grows near Delhi and Form V grows near Delhi and Ahmadabad.

Various agro climatic conditions also influence the phytoconstituents, hence an effort was made in the present investigation to evaluate Ashwagandha root samples from four different regions of India viz. Lucknow (WsL), Karnataka (WsK), Mumbai (WsM), and Nimuch (WsN) for their withanolide-A contents. 


\section{Materials and methods}

Withania somnifera plants were collected in winter season from different regions of India viz. Lucknow, Karnataka, Nimuch and Mumbai. The authenticity of the plant materials was conformed at the Department of Botany, Institute of Science, Mumbai.

\section{Extraction of the plant materials}

The roots were cleaned, air dried and crushed into coarse powder using mortar and pestle. $10 \mathrm{gm}$ of powdered roots were extracted with $250 \mathrm{ml}$ of methanol for $36 \mathrm{hrs}$ using Soxhlet apparatus. The extract was evaporated on water bath to $25 \mathrm{ml}$ (Trease and Evans, 1989).

\section{Preliminary phytochemical analysis}

Roots extracts were analyzed for alkaloids, flavonoids, tannins, saponins, anthroquinones, sterols, triterpenes and glycosides by HPTLC method.

\section{HPTLC analysis for withanolide-A}

Samples were analyzed for withanolide-A by HPTLC technique and UV spectral analysis using WINCAT software (CAMAG, Switzerland) supplied by Anchrom Pvt. Ltd., Mumbai. Precoated TLC plates (Silicagel 60 $\left.\mathrm{F}_{254}\right)$ of $0.2 \mathrm{~mm}$ thickness and $20 \times 20 \mathrm{~cm}$ size were purchased from Merck (KGaA, Germany) and standard withanolide-A was purchased from Natural Remedies (Bangalore). The stock solution of standard withanolideA was prepared in methanol $(1 \mathrm{mg} / \mathrm{ml})$. $5 \mu \mathrm{l}$ sample extracts were loaded as an $8 \mathrm{~mm}$ streak on HPTLC at $10 \mathrm{~mm}$ distance between two streaks using a Linomat IV, an automatic spotter. The solvent system used was Chloroform: Methanol (9:1) (Mukherjee, 2002).

After drying, plates were scanned and chromatograms were recorded. Spectra, $\mathrm{R}_{\mathrm{f}}$ values, AUC and $\lambda$ max of withanolide-A of all the samples were recorded. Plates were derivatized using Anisaldehyde sulphuric acid, observed under $254 \mathrm{~nm}$, and $366 \mathrm{~nm}$ as well as under white light.

\section{Calibration studies}

Linearity for withanolide-A was evaluated in the range of 3.0-7.0. $\mu \mathrm{g} \mathrm{mL} \mathrm{m}^{-1}$, peak area versus concentration was subjected to least square linear regression analysis and the slope, intercept and correlation coefficient for calibration were determined. Limit of detection (LOD) and quantification (LOQ) were determined from the calibration curve using expression $3 \sigma / \mathrm{s}$ and $10 \sigma / \mathrm{s}$ where $\sigma$ is standard deviation and $\mathrm{s}$ is the slope of calibration curve. Accuracy of method was evaluated through the percentage recoveries of known amounts of withanolide-A.

\section{GC-MS Analysis}

The GC-MS analysis of methanolic root extracts of Withania somnifera collected from different climatic region of India was performed using an Agilent Technologies GC-System HP5 coloumngas chromatography equipped with a Elite-5 capillary column (5\% Diphenyl 95\% dimethyl poly siloxane) $(30 \mathrm{~nm} \times 0.25 \mathrm{~mm}$ ID $\times 0.25 \mu \mathrm{mdf})$ and mass detector tub mass gold of the company which was operated in EI mode. Helium was the carriers gas at a flow rate of 1 $\mathrm{ml} / \mathrm{min}$. the injector was operated at $200^{\circ} \mathrm{C}$ and the oven temperature was programmed as follows: $60^{\circ} \mathrm{C}$ for $15 \mathrm{~min}$, then gradually increased to $270^{\circ} \mathrm{C}$ at $3 \mathrm{~min}$. the identification of components to was based on comparison of their mass spectra with those of Wiley and NIST Libraries and those described by Adams as well as on comparison of their retention indices Senthis with literature.

\section{Results and discussion}

Preliminary phytochemical analysis using chemical tests revealed presence of alkaloids, flavonoids, tannins, saponins, sterols, triterpenes and glycosides. Anthraquinones could not be detected either in leaf or root extracts (Table 1).

Table 1. Preliminary phytochemical analysis of methanolic root extracts of Withania somnifera from selected regions.

\begin{tabular}{lll}
\hline Sr. & Phytochemicals & Roots \\
No. & Alkaloids & + \\
\hline 1. & Flavonoids & + \\
2. & Tannins & + \\
3. & Saponins & + \\
4. & Anthraquinones & - \\
5. & Sterols & + \\
6. & Triterpenes & + \\
7. & Glycosides & + \\
\hline 8. & & \\
\hline
\end{tabular}

Phytochemical fingerprinting of root extracts by HPTLC

Presence of secondary metabolites detected by preliminary method was confirmed by HPTLC analysis. The results are depicted in (Table 2). The correlation coefficient of withanolide-A was found to be 0.997 . The peak area (y) is proportional to the concentration of withaferin-A (x) following 
the regression equation $y=40.742+1.949 x$. (Fig. 1) Experimentally derived LOD and LOQ was 300 and 700 $\mathrm{ng} / \mathrm{mL}^{-1}$.

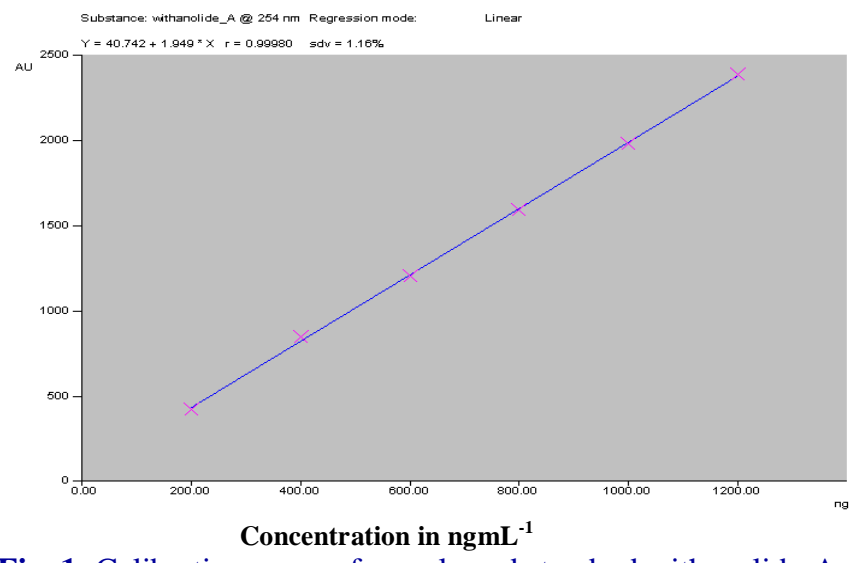

Fig. 1: Calibration curve of sample and standard withanolide-A.

Table 2. Phytochemical fingerprinting of methanolic root extracts of Withania somnifera by HPTLC.

\begin{tabular}{lll}
\hline $\begin{array}{l}\text { Sr. } \\
\text { No. }\end{array}$ & Phytochemicals & Roots \\
\hline 1. & Alkaloids & + \\
2. & Flavonoids & - \\
3. & Tannins & - \\
4. & Saponins & + \\
5. & Anthraquinones & - \\
6. & Sterols & + \\
7. & Triterpenes & + \\
8. & Glycosides & + \\
\hline
\end{tabular}

Stability: Stability of withanolide-A solution was evaluated to verify whether spontaneous degradation occurred within 2 days. The results were calculated as the percentage content of the standards at 24 and 48 hours. Standard showed less than $5 \%$ degradation at investigated temperature (Table 3 ).

Table 3. Stability of standard withanolide-A (\%).

\begin{tabular}{llll}
\hline Phytochemical & Temperature & 24hrs & 48hrs \\
\hline Withanolide-A & $4^{\circ} \mathrm{C}$ & 96.9904 & 92.448 \\
\hline
\end{tabular}

Table 4. Results of recovery studies of withanolide-A

\begin{tabular}{ll}
\hline Concentration & Recovery $(\%)$ \\
\hline $0.2 \mu \mathrm{g}$ & 60.7 \\
$0.3 \mu \mathrm{g}$ & 66 \\
$0.4 \mu \mathrm{g}$ & 63 \\
\hline
\end{tabular}

Precision studies showed RSD less than $1 \%$ indicating sufficient precision. Recovery studies $(60.7 \%$ to $66 \%)$ indicated that the method was reliable for the quantification of withanolide-A (Table 4) in the test samples. Results of method validation are in keeping with those of (Jirge et al., 2011; Silvia, 2010; Rothenbuhler, 2010).

The HPTLC analysis showed the presence of withanolide-A was confirmed by comparing with the standard peak of withanolide-A (Fig. 1). Maximum $\mathrm{R}_{\mathrm{f}}$ of Withanolide-A was 0.65 for all the test sample which was very close to 0.64 of standard withanolide-A (Fig. 2). Lamda of test sample and standard for withanolide-A is shown in (Fig. 3). WithanolideA content ranged from 0.4 to $1.3 \%$. Maximum quantity was detected in WSN (1.3\%) followed by WSK (1.2\%) WSM $(0.7 \%)$ and WSL $(0.4 \%)$ (Table 5).

Table 5. Withanolide-A content of Ashwagandha collected from different regions of India.

\begin{tabular}{lll}
\hline Sr. No. & Sample & Withanolide-A (\%) \\
\hline 1 & WsL & 0.4 \\
2 & WsK & 1.2 \\
3 & WsN & 1.3 \\
4 & WsM & 0.7 \\
\hline
\end{tabular}

\section{GC-MS analysis}

Using GC-MS, the linear retention indices for all the compounds were determined by coinjection of the sample. The individual constituents were identified by their identical retention indices, referring to known compounds from literature (Adam, 1995) and also by comparing their mass spectra with either the known compounds or with Wiley mass spectral database. More number of compounds was detected in leaves than in roots.

\section{Identification of phytochemicals from leaf extract}

Maximum number of chemicals (12) could be detected in the leaf collected from Nimuch region. Karnataka and Lucknow samples gave four and three peaks respectively while leaves collected from Mumbai region gave only two peaks. DL-Proline, 5-oxo, methyl ester was a common compound detected in leaves of WSM and WSK region where as 1- Phenylalanine, methyl ester was unique to WSM and Quinic acid, n-Hexadecanoic acid and 9,12,15Octadecatrienoic acid to WSK. Similarly, 9H-Pyrido [3,4-b] indole was a common compound in leaf samples of Nimuch and Lucknow. All the other compounds (11-in WSN and 2in WSL) were unique to that particular region (Table 6).

\section{Identification of phytochemicals from root extract}

Based on peak area, molecular weight a total of 15 compounds were identified from root extract Withania somnifera from four different regions. Maximum numbers of peaks were detained (6) for Nimuch area followed by Lucknow (4) and minimum being Mumbai and Karnataka (3 each). None of the constituents identified from the roots were common to any of the selected region (Table 7). 


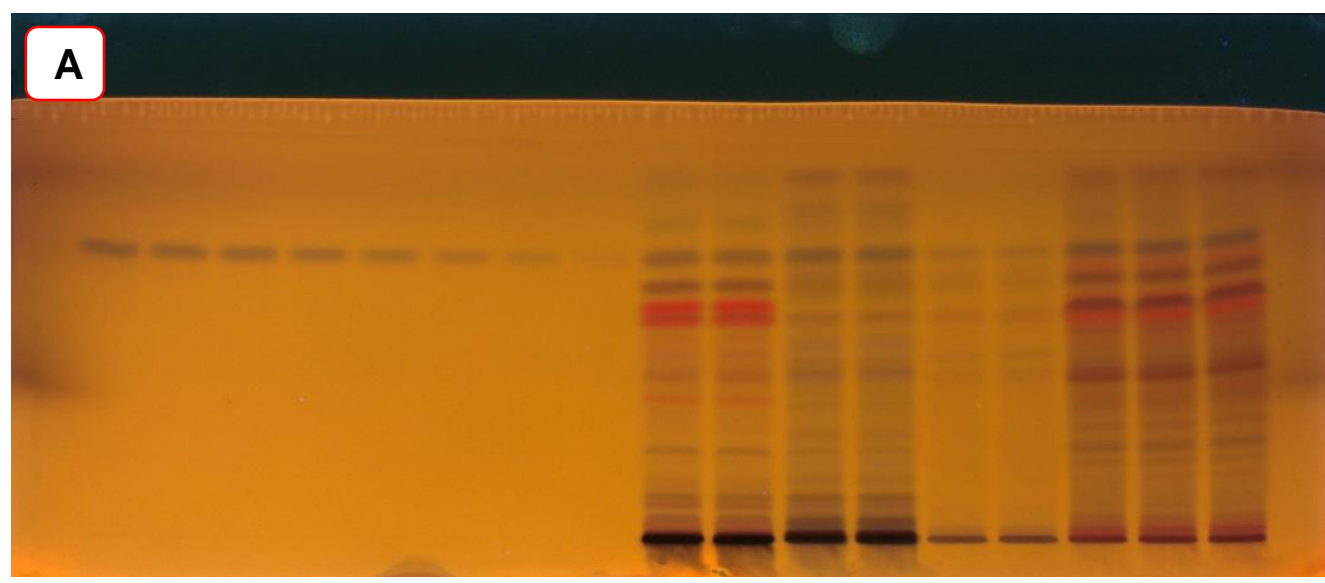

STD STD STD STD STD STD STD WsN WsN WsM WsM WsL WsL WsK WsK WsK

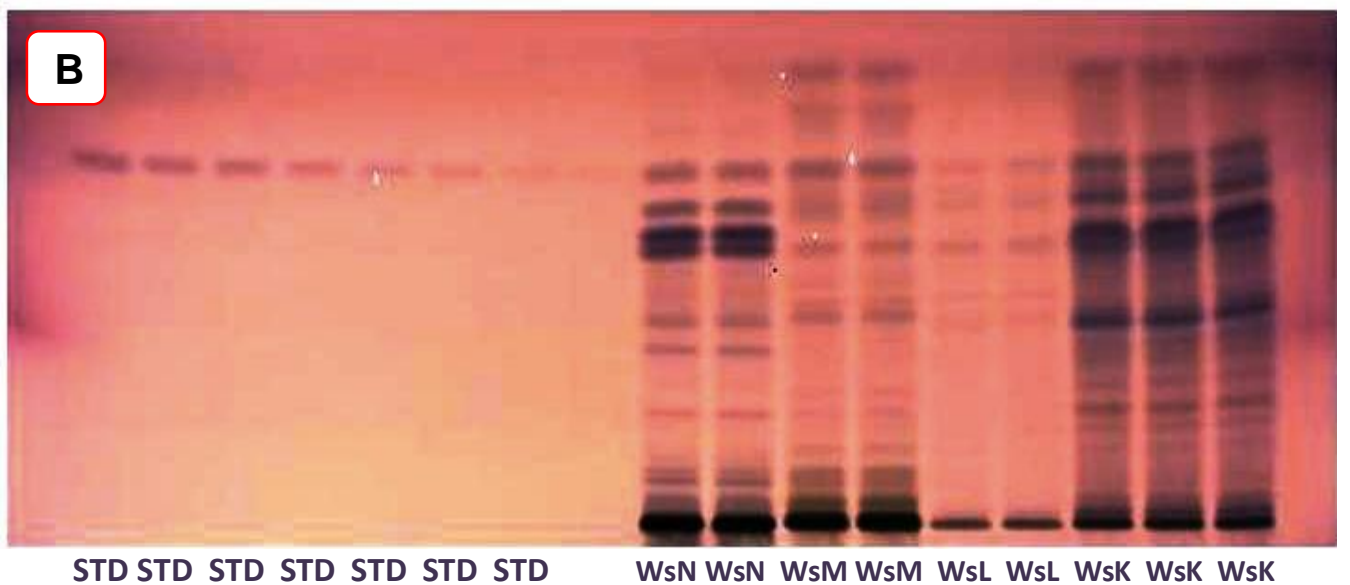

Fig. 2: HPTLC profile of Ashwagandha test sample - Withanolide-A content in Withania somnifera. (A) After derivatization - image of fluoresces at 366nm. (B) Image of white light.

Table 6. GC-MS detection of other phytochemicals from methanolic leaf extracts of Withania somnifera from selected regions.

\begin{tabular}{llll}
\hline \multirow{2}{*}{ Sample } & Details of compounds detected & & \\
\cline { 2 - 4 } & Name & Retention time (min.) & Molecular formula \\
\hline \multirow{2}{*}{ WsM } & DL-Proline,5- oxo, methyl ester & 7.4 & $\mathrm{C}_{6} \mathrm{H}_{9} \mathrm{NO}_{3}$ \\
& 1-Phenylalanine, methyl ester & 8.1 & $\mathrm{C}_{10} \mathrm{H}_{13} \mathrm{NO}_{2}$ \\
\hline & DL-Proline,5-oxo, methylester & 7.4 & $\mathrm{C}_{6} \mathrm{H}_{9} \mathrm{NO}_{3}$ \\
& Quinic acid & 10.4 & $\mathrm{C}_{7} \mathrm{H}_{12} \mathrm{O}_{6}$ \\
& n-Hexadecanoic acid & 14.1 & $\mathrm{C}_{16} \mathrm{H}_{32} \mathrm{O}_{2}$ \\
& 9,12,15-Octadecatrienoic acid & 15.8 & $\mathrm{C}_{18} \mathrm{H}_{30} \mathrm{O}_{2}$ \\
\hline WsN & Pyrrolidine, 1-[1-(phenylmethyl)butyl] & 3.5 & $\mathrm{C}_{15} \mathrm{H}_{23} \mathrm{~N}$ \\
& D-Alanine,N-Propargyloxycarbonyl-, isohexyl ester & 3.5 & $\mathrm{C}_{13} \mathrm{H}_{21} \mathrm{NO}_{4}$ \\
& 4H-Pyran-4-one,2,3-dihydro-3,5-dihydroxy-6-methyl & 4.4 & $\mathrm{C}_{6} \mathrm{H}_{8} \mathrm{O}_{4}$ \\
& 2-Furancarboxaldehyde,5-(hydroxymethyl)- & 5.4 & $\mathrm{C}_{6} \mathrm{H}_{6} \mathrm{O}_{3}$ \\
& Octanamide.N-(2-mercaptoethyl)- & 6.1 & $\mathrm{C}_{10} \mathrm{H}_{21} \mathrm{NOS}$ \\
& 1,3-Diazacyclooctane-2-thione & 6.1 & $\mathrm{C}_{6} \mathrm{H}_{12} \mathrm{~N}_{2} \mathrm{~S}$ \\
& Geranyl isovalerate & 8.5 & $\mathrm{C}_{15} \mathrm{H}_{26} \mathrm{O}_{2}$ \\
& Guanosine & 8.5 & $\mathrm{C}_{10} \mathrm{H}_{13} \mathrm{~N}_{5} \mathrm{O}_{5}$ \\
& Ppropiolic acid, 3-(1-hydroxy-2-isopropyl-5-methylcyclohexyl)- & 12.3 & $\mathrm{C}_{13} \mathrm{H}_{20} \mathrm{O}_{3}$ \\
& 2-Pentyne-1,4-diol,4-methyl-1-(2-thienyl)- & 12.3 & $\mathrm{C}_{10} \mathrm{H}_{12} \mathrm{O}_{2} \mathrm{~S}$ \\
& 9H-Pyrido[3,4-b] indole & 14.4 & $\mathrm{C}_{11} \mathrm{H}_{8} \mathrm{~N}_{2}$ \\
& 1-Naphthalenecarbonitrile,8-amino- & 14.4 & $\mathrm{C}_{11} \mathrm{H}_{8} \mathrm{~N}_{2}$ \\
\hline WsL & 13.Oxadispiro [5.0.5.1] tridecan-1-one & 10.4 & $\mathrm{C}_{12} \mathrm{H}_{18} \mathrm{O}_{2}$ \\
& 2H-Cyclodeca[b]pyran, 3,4,5,6,7,8,9,10,11,12-decahydro-4-methyl- & 10.4 & $\mathrm{C}_{14} \mathrm{H}_{24} \mathrm{O}$ \\
& 9H-Pyrido[3,4-b] indole & 14.4 & $\mathrm{C}_{11} \mathrm{H}_{8} \mathrm{~N}_{2}$ \\
\hline
\end{tabular}


Table 7. GC-MS detection of other phytochemicals from methanolic root extracts of Withania somnifera from selected regions.

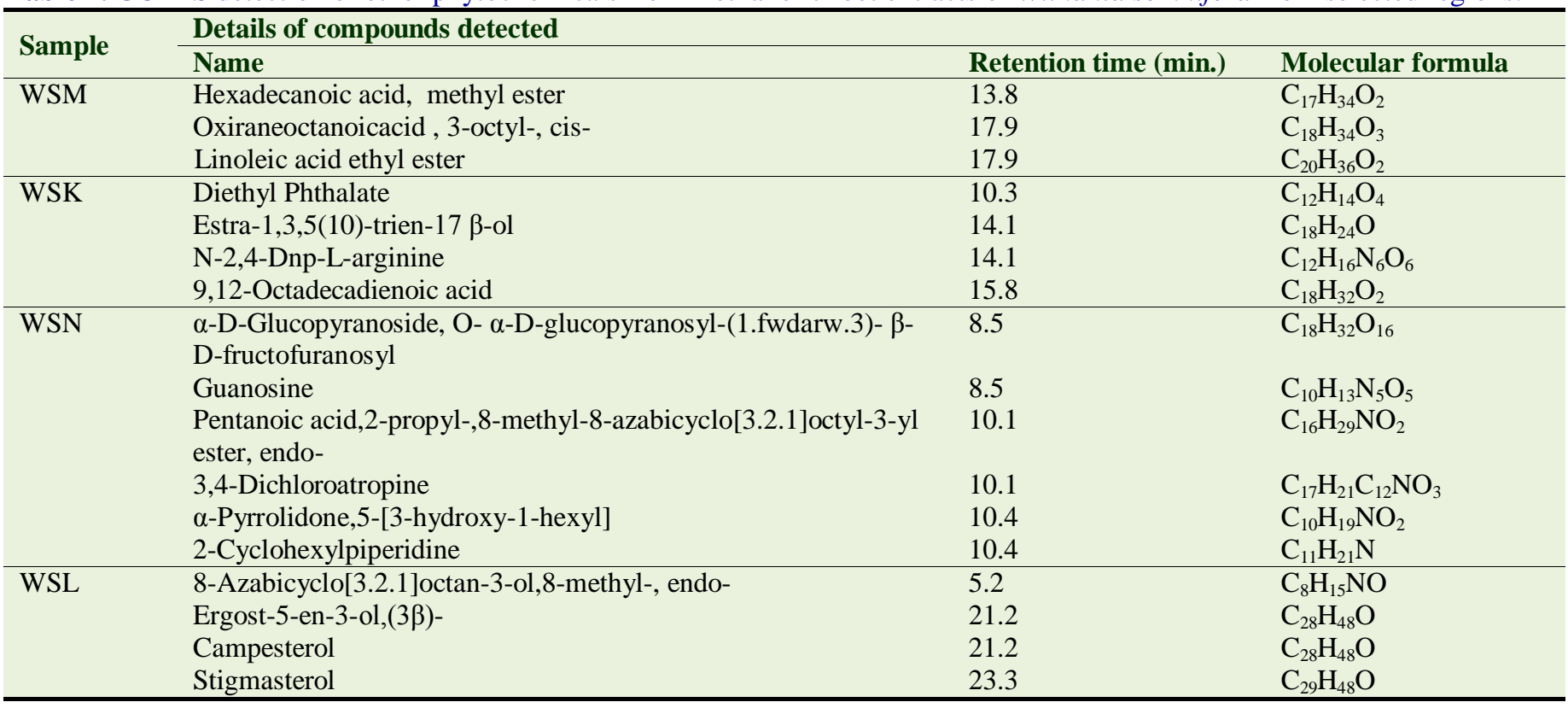

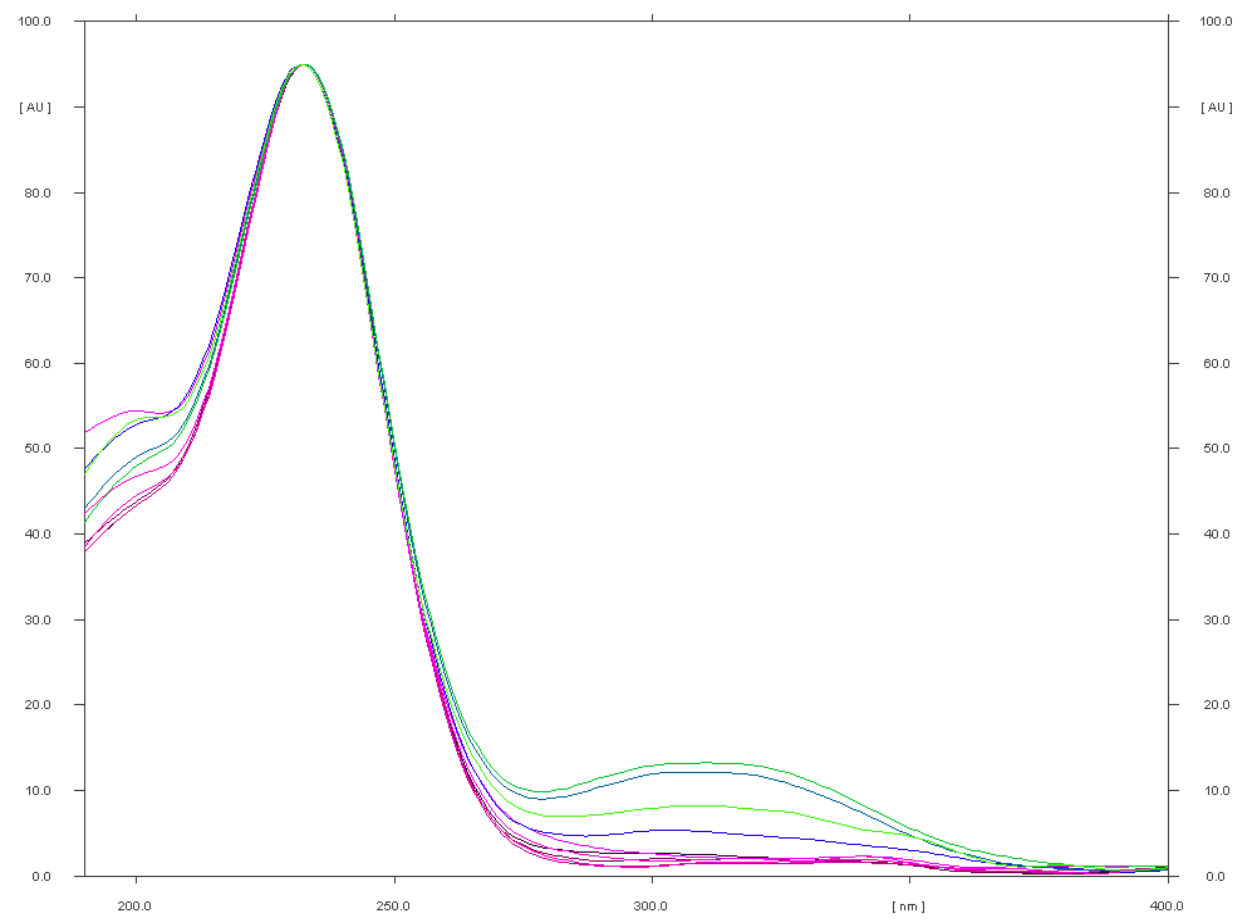

Fig. 3: Lamdamax of Ashwagandha test samples corresponding to Standard withanolide-A.

The formation of secondary metabolites is known to be highly influenced by varied climatic condition prevalent in different geographical regions. Hence, we have tested the metabolites present in crude extract of roots of Withania somnifera taken from several regions in India. Plants cultivated in four different states of India viz.,
Madhya Pradesh (Nimuch), Uttar Pradesh (Lucknow), Maharashtra (Mumbai) and Karnataka (Kalasapur) were selected for the study. Our earlier data showed that the plants collected in the same season and identical age of the plants showed differing content of withaferin-A (Shah and Khan, 2012). The regional differences in 
levels of the secondary metabolites are perhaps due to prevalent climatic conditions. Our data suggest that it is important to select and obtain the plant samples, for research or manufacturing after screening from various regions.

Withania somnifera is chemically very complex and more than 80 compounds are known from it (Van Wyk et al., 2000). Different parts of the plant contain a number of chemical compounds like alkaloids, steroidal compounds, steroidal lactones, saponins, glycosides, tannins etc. (Costa et al., 1999; Rajeshwar and Lalitha, 2013). This necessitates phytochemical profiling of the plant. The plants from selected regions were fingerprinted for their phytochemicals by spot tests, HPTLC and GC-MS method.

Preliminary phytochemical analysis of methanolic leaf and root extracts revealed the presence of alkaloids, saponins, sterols, triterpenes and glycosides. Anthraquinones could not be detected in any of the samples. HPTLC fingerprinting did not resolve flavonoids, tannins and anthraquinones. Withania somnifera has been shown to display an appreciable spectrum of phytochemical variability (Kumar et al., 2007). Therefore, a large number of researchers have profiled various parts of this medicinal plant for its phytochemicals. Visweswari et al. (2013) reported presence of alkaloids, flavonoids, steroids, saponins, phenols and glycosides from the methanolic extracts of dried roots of this plant and reported absence of terpenoids and tannins. Work of Saidulu et al. (2014) also revealed presence of flavonoids, alkaloids, glycosides, sterols, phenols, terpenoids, saponins, tannins and cardiac glycosides in methanolic extracts of roots, leaves and stems of Ashwagandha. Flavonoids were shown to be absent in ethanolic extracts of leaves and stems of Withania by Pralhad and Mishra (2014) though it could be detected in root extracts. Santhi and Swaminathan (2011) also reported glycosides, alkaloids, phytosterols, phenolics and flavonoids in Ashwagandha leaves extracted with water, ethanol and acetone. Presence of these secondary metabolites was also illustrated by Singh et al. (2010) in ethanolic root extracts.

GC-MS analysis of methanolic leaf and root extracts was performed, the identification of compounds was made on the basis of comparison of their mass spectra with those of Wiley and NIST Libraries and those described by Adam (1995) as well as on comparison of their retention indices (Vanden and Kratz, 1963) with literature. A total of 12 compounds could be detected in leaves and 15 in roots.
Maximum number of phytochemicals could be detected in the leaf (12) and root (06) samples obtained from Nimuch region. Except for DL-Proline, 5-oxo, methyl ester which was common to WSM and WSK leaves and 9H-Pyrido [3,4-b] indole common to WSN and WSL leaves, each sample had its own unique profile. Roots from four selected regions did not show any similarity in their phytoconstituents. Twenty one constituents were analyzed in alcoholic root extracts of Withania somnifera (Senthil Kumar et al., 2011). One of the constituents being $n$-Hexadecanoicacid which is reported in leaf extract and its methyl ester in root extracts of our study.

The constituents of Withania somnifera roots are the steroidal alkaloids and steroidal lactones. They belong to a class of constituents called withanolides (Elsakka et al., 1990; Mishra et al., 2000) with the main active chemical constituent withaferin-A, a phytosterol (Lavie et al., 1965). Much of the pharmacological activity of Withania somnifera has been attributed to two main withanolides viz., withaferin-A and withanolide-D (Sharma et al., 2011). The leaves of Indian chemotype are reported to contain 12 withanolides. The leaves of the plant from different habitat contain different Withanolides- a group of C28 steroids (Uddin et al., 2012).

\section{Conclusions}

The present study can be used in future for economical formulations of the active chemical ingredients in natural drugs against a variety of inflammatory diseases. No significant correlation could be drawn between edaphic factors and Withanolide contents indicating that phytochemical variations are by and large gene related. Probably more than one chemotypes of this plant of medicinal value exists in India. Further studies probably at the gene expression level will be necessary to ascertain the causes of phytochemical diversity, variations in the quantity of phytochemicals and difference in the medicinal potential of plants from one region to another.

\section{Conflict of interest statement}

Authors declare that they have no conflict of interest.

\section{Acknowledgement}

Authors are thankful to University Grant Commission (UGC), Government of India, New Delhi, for awarding Maulana Azad National Fellowship and also thank Dr. MoinuddinVakil, for their support and help. 


\section{References}

Adam, R., 1995. Identification of Essential Oil Components by Gas Chromatography/Mass Spectroscopy. Allured Publishing Co., Carol Stream, IL.

Costa, M.A., Zia, Z.Q., Davin, L.B., Lewis, N.G., 1999. Chapter Four: Toward Engineering the Metabolic Pathways of Cancer-Preventing Lignans in Cereal Grains and Other Crops. In: Phytochemicals in Human Health Protection, Nutrition, and Plant Defense (Ed.: Romeo, J.T.). Recent Advances in Phytochemistry, Vol. 33, New York. pp.67-87.

Elsakka, M., Grigorescu, E., Stanescu, U., Stanescu, U., Dorneanu, V., 1990. New data referring to chemistry of Withania somnifera species. Rev. Med. Chir. Soc. Med. Nat. Iasi. 94, 385-387.

Indian Pharmaecopoeia, Ashwagandha, 1985. Ministry of Health and Family Welfare, Government of India, Controlles of Publication, Delhi. Appendix 3.3. 10, 69.

Jirge, S.S., Tatke, P.A., Gabhe, S.Y., 2011. Development and validation of a novel HPTLC method for simultaneous estimation of $\beta$ sitosterol-D glucoside and withaferin-A. Int. J. Pharm. Pharmaceut. Sci. 3(Suppl. 2), 227-230.

Kapoor, L.D., 1990. CRC Handbook of Ayurvedic Medicinal Plants, Boca Raton, FL CRC Press, Inc. pp.337-338.

Kumar, A., Kaul, M.K., Bhan, M.K., Khanna, P.K., Suri, K.A., 2007. Morphological and chemical variation in 25 collections of the Indian medicinal plant Withania somnifera (L.) Dunal (Solanaceae). Genet. Resour. Crop Evol. 54, 655-660.

Lavie, D., Glotter, E.S., 1965. Constituents of Withania somnifera-III. The side chain of Withaferin A. J. Org. Chem. 30, 1774-1778.

Mishra, L.C., Singh, B.B., Dagenais, S., 2000. Scientific basis for the therapeutic use of Withania somnifera (Ashwagandha), a review. Alt. Med. Rev. 5, 334-346.

Mukherjee, P.K., 2002. Quality Control of Herbal Drugs -

An Approach to Evaluation of Botanicals. ${ }^{\text {st }}$ Edn. Business Horizons, New Delhi, India.

Pralhad, D. N., Mishra, R. L., 2014. Preliminary Phytochemical studies on Withania somnifera, Datura stramonium and Solanum surattenses from district of Raigad, Maharashtra State (India). Int. Multidiscip. Res. J. II(V), 35-39.

Pulak, K.M., 2002. Quality Control of Herbal Drugs. An Approach to Evaluation of Botanicals, Business Horizons, pp.764-766.

Rajeshwar, Y., Lalitha, R., 2013. Preliminary phytochemical screening and in vitro anthelmintic effects of Acmella paniculata plant extracts. Biolife. 1(3), 106-112.
Shah, R.A., Khan, S., 2012. Evaluation of Withaferin-A in Ashwagandha's leaves from different climatic regions of India. Adv. Plant Sci. 25(II), 709-711.

Rothenbuhler, K., 2010. Validated HPTLC Method for Skin Lipids. CBS. 104. CAMAG Scientific Inc., USA. pp.5-6.

Saidulu, Ch., Venkateshwar, C., Gangadhar Rao, S., 2014. Preliminary phytochemical studies of medicinal plant drug: Withania somnifera Linn. Biolife. 2(1), 306-312.

Santhi, M., Swaminathan, C., 2011. Evaluation of antibacterial activity and phytochemical analysis of leaves of Withania somnifera (L.) Dunal. Int. J. Curr. Res. 33(3), 10-12.

Senthil Kumar, M., Vinoth Kumar, D., Saravana Kumar, A., Aslam, A., Shajahan, A., 2011. The phytochemical constituents of Withania somnifera and Withania obtusifolia by GCMS analysis. Int. J. Pharmacog. Phytochem. Res. 3(3), 31-34.

Sharma, V., Sharma, S., Pracheta, Paliwal, R., 2011. Withania somnifera: A rejuvenating ayurvedic medicinal herb for the treatment of various human ailments. Int. J. PharmTech Res. 3, 187-192.

Silvia, C., 2010 Validated determination of secoisolariciresinol -diglucoside in flax seed by HPTLC. CBS 104. CAMAG Scientific Inc., USA. pp.10-12.

Singh, A., Duggal, S., Singh, H., Singh, J., Katekhaye, S., 2010. Withanolides: Phytoconstituents with significant pharmacological activities. Int. J. Green Pharm. 4, 229-237.

Trease, G.E., Evans, M.C., 1989. Text Book of Pharmacognosy. $13^{\text {th }}$ Edn., Bailliere, Tindal, London. pp.683-684.

Tripathi, A.K., Shukla, Y.N., Kumar, S., 1996. Ashwagandha (Withania somnifera): A status report. J. Med. Arom. Plant Sci. 18, 46-56.

Uddin, Q., Samiulla, L., Singh, K.V., Jamil, S.S., 2012. Phytochemical and pharmacological profile of Withania somnifera Dunal: A review. J. Appl. Pharmaceut. Sci. 2 (1), 170-175.

Van Wyk, B.E., Van Oudtshoorn, B., Gericke, N., 2000. Medicinal Plants of South Africa. Briza Publications. pp.38-39.

Vanden, D.H., Kratz, P.D., 1963. A generalization of retention index system including linear temperature programmed gas-liquid partition chromatography. J. Chromatogr. 11, 463-471.

Visweswari, G., Christopher, R., Rajendra, W., 2013. Phytochemical screening of active secondary metabolites present in Withania somnifera root: role in traditional medicine. Int. J. Pharm. Sci. Res. 4(7), 2770-2776.

Wagner, H,, Bladt, S,, Zgainski, E.M., 1984. Plant Drug Analysis - A Thin Layer Chromatography Atlas. Springer -Verlag, Berlin.

\section{How to cite this article:}

Shah, R. A., Khan, S., Rehman, W., Vakil, M., 2016. Phytochemical evaluation of withanolide-A in ashwagandha roots from different climatic regions of India. Int. J. Curr. Res. Biosci. Plant Biol. 3(2), 114-120. doi: http://dx.doi.org/10.20546/ijcrbp.2016.302.014 